\title{
Doğal bir kollajen çapraz bağlayıcının kendinden bağlanabilen akışkan kompozitlerin dentin bağlanma dayanımına etkisi*
}

\author{
Seda Can ${ }^{1}$, Firdevs Kahvecioğlu², Hamdi Acar ${ }^{3}$, Mustafa Ülker ${ }^{4}$
}

Selcuk Dent J, 2016; 3: 63-68

Bașvuru Tarihi: 20 Ocak 2016 Yayına Kabul Tarihi: 15 Nisan 2016

öz

Doğal bir kollajen çapraz bağlayıcının kendinden bağlanabilen akışkan kompozitlerin dentin bağlanma dayanımına etkisi

Amaç: $\mathrm{Bu}$ in vitro çalışmanın amacı proantosiyanidinden zengin bir özütün (üzüm çekirdeği özütü), kendinden bağlanabilen akışkan kompozitlerin [VertiseFlow, Kerr; Fusio Liquid Dentin, Pentron; NovaCompo SF, Imicryl] dentin makaslama bağlanma dayanımlarına etkisini incelemektir.

Gereç ve Yöntemler: Bu çalışmada 90 adet çürüksüz insan üçüncü molar dişi kullanıldı. Dişlerin tüberkülleri uzaklaştırılarak düz okluzal dentin yüzeyleri hazırlandı. Dentin yüzeyleri \#600 grenli zımpara kâğıdı ile zımparalandıktan sonra rastgele 6 gruba ayrıldı $(n=15)$. Deney gruplarına ait dentin yüzeylerine kompozitleri bağlamadan önce bu yüzeyler \%20'lik üzüm çekirdeği özütü ile muamele edildi. Kompozitler silindirik şekilli plastik matrisler içinde uygulandı ve ışık ile sertleştirildi. Makaslama bağlanma dayanımı için her bir örneğin diş-kompozit ara yüzeyinde kırılma meydana gelinceye kadar $1 \mathrm{~mm} / \mathrm{dk}$ hızda kuvvet uygulandı. Veriler One-Way ANOVA ve Tukey's HSD Post-hoc testleri ile analiz edildi.

Bulgular: Nova Compo SF ve Vertise Flow için, üzüm çekirdeği özütü ile muamele edilen gruplar ile kontrol gruplarını dentin bağlanma dayanımları arasında fark yoktu $(p>0.05)$. Ancak, dentinin üzüm çekirdeği özütü ile muamele edilmesi Fusio Liquid Dentin'in dentine bağlanma dayanımını düşürdü $(p<0.05)$.

Sonuç: Kollajen çapraz bağ ajanı olarak kullanılan \%20'lik üzüm çekirdeği özütü, kendinden bağlanabilen akışkan kompozitlerin dentine bağlanma dayanımlarını artırmadı. Bunlara ilaveten, Fusio Liquid Dentin'in, dentine bağlanma dayanımın olumsuz etkiledi.

\section{ANAHTAR KELIMELER}

Dental bağlanma, makaslama gücü, rezin dental kompozit

\section{ABSTRACT \\ Effect of a natural collagen cross-linker on dentin bond} strengths of self-adhering flowable composites

Background: The aim of this in vitro study was to investigate the effects of a proanthocyanidin-rich extract (grape seed extract) on the dentin shear bond strength of self-adhering flowable composites [Vertise Flow, Kerr; Fusio Liquid Dentin,Pentron; NovaCompo SF, Imicryl]

Methods: Ninety extracted caries free human third molar teeth were used. Cusps of teeth were removed and flat occlusal dentin surfaces were prepared. Dentin surfaces ground with \#600-grit SiC paper. The samples were randomly divided into 6 groups $(n=15)$. Dentin surfaces of experimental groups were treated with $20 \%$ grape seed extract for $1 \mathrm{~min}$ before bonding the composites. Composites were applied by cylindrical shaped plastic matrixes and light cured. For shear bond testing, force was applied at a cross head speed of $1 \mathrm{~mm} /$ minute to each specimen at the interface between the tooth and composite until failure occurred. The data were analyzed by One-Way ANOVA and Tukey's HSD Post-hoc tests.

Results: For Nova Compo SF and Vertise Flow, statistically there were no difference between the dentin bond strengths of grape seed extract treated groups and control groups $(p>0.05)$. However, grape seed extract treatment decrease the dentin bond strength of Fusio Liquid Dentin $(p<0.05)$.

Conclusion: Grape seed extract $(20 \%)$ that is used as a collagen cross-linker did not increase the dentin bond strength of self-adhering flowable composites. Moreover, grape seed treatment adversely affected the dentin bond strength of Fusio Liquid Dentin.

\section{KEYWORDS}

Dental bonding, shear strength, composite dental resine

hekimlerin restoratif işlemleri en az diş dokusu kaybı ile sonuçlandırmak istemeleri, adeziv diş hekimliğindeki hızlı gelişmeleri beraberinde getirmiştir (Cardoso ve ark. 2011).
Günümüz restoratif diş hekimliğinin odaklandığı konulardan birisi de adeziv bağlayıc sistemler ve minimal girişimsel teknikleri bir arada kullanarak çürük, kırık ya da hasarlı dişleri tedavi edebilmektir. Hastaların artan estetik talebi ve bunun yanında

\footnotetext{
${ }^{*}$ Bu çalışma 2014 yılı Kasım ayında İstanbul'da düzenlenen 8. Uluslararası Akdeniz Ülkeleri Pedodonti Dernekleri \& 21. Türk Pedodonti Derneği Kongresinde sunulmuştur.

${ }^{1}$ Diş Hekimi, İstanbul

${ }^{2}$ Selçuk Üniversitesi Diş Hekimliği Fakültesi Pedodonti Anabilim Dalı, Konya

${ }^{3}$ Beyhekim Ağız ve Diş Sağlı̆̆ Merkezi, Konya

${ }^{4}$ Selçuk Üniversitesi Diş Hekimliği Fakültesi Restoratif Diş Tedavisi Anabilim Dalı, Konya
} 
Adeziv rezin/kompozit rezin kombinasyonu günümüz diş hekimliği pratiğinde en sık kullanılan restoratif sistemdir. Günümüz adezivleri etki mekanizmasına göre asitle ve yıka (etch\&rinse) ve kendinden asitli (self-etch) olmak üzere iki temel sınifta incelenmektedir (Van Meerbeek ve ark. 2005, Ülker ve Belli 2006, Van Landuyt ve ark. 2007, Cardoso ve ark. 2011, Belli ve Ülker 2015). Asitle ve yıka sistemler ayrı bir asitleme ve yıkama basamağı içerdiğinden klinik uygulama zamanını uzatmaktadır. Ayrıca, yüksek oranda aseton çözücü içeren bazı asitle ve yıka sistemlerin teknik hassasiyetleri oldukça yüksektir (Ülker ve Belli 2006, Belli ve Ülker 2015). Kendinden asitli sistemlerde ise ayrıca asitleme ve yıkama basamağı bulunmaz. Primere eklenen zayıf asidik fonksiyonel monomerler yıkama/kurutma gereksinimi ortadan kaldırmışıı ve dolayısı ile adeziv uygulama işleminin teknik hassasiyeti de oldukça azalmıştır (Belli ve Ülker 2015). Asit, primer ve adeziv uygulamalarının tamamını tek şişede (all in one) buluşturan tek basamaklı kendinden asitli sistemler ile klinik uygulama süresi daha da kısaltılmıştır (Ülker ve Belli 2006, Ülker ve ark. 2010, Belli ve Ülker 2015). Ancak, tek basamaklı kendinden asitli sistemler bile azımsanmayacak bir klinik uygulama zamanına ve kendilerine özgü bazı teknik hassasiyetlere sahiptirler (Belli ve Ülker 2015).

Adeziv diş hekimliğindeki son gelişmeler ile diş sert dokularına herhangi bir adeziv sistem kullanımı gerekmeden bağlanan akışkan kompozitler hekimlerin kullanımına sunulmuştur (Poss 2010).

Kendinden bağlanabilen akışkan kompozitlerin diş sert dokularına bağlanma performansı ile ilgili sınırlı sayıdaki araștırma sonuçlarına göre diş sert dokularına bağlanma dayanımları henüz istenildiği kadar yüksek değildir (Goracci ve ark. 2013,Vichi ve ark. 2013). Dentine bağlanma dayanımını arttırmak için günümüzde önerilen yöntemlerden birisi de dentin yüzeylerinin adeziv bağlayıcı ajan kullanımı öncesinde dentinin kollajen çapraz bağ ajanları ile muamele edilmesidir (Bedran-Russo ve ark. 2013). Doğal olması nedeniyle en çok rağbet gören ajan, üzüm çekirdeği özütünden elde edilen proantosiyanidindir (Bedran-Russo ve ark. 2013). $\mathrm{Bu}$ in vitro çalışmanın amacı, kollajen çapraz bağ ajanı olarak kullanılan proantosiyanidinden zengin bir özütün (üzüm çekirdeği özütü), kendinden bağlanabilen akışkan kompozitlerin dentin makaslama bağlanma dayanımlarına etkisini incelemektir. Bu çalışmanın sıfır hipotezi şudur: kollajen çapraz bağ ajanı olarak kullanılan üzüm çekirdeği özütü ile dentinin muamele edilmesi, kendinden bağlanabilen akışkan kompozitlerin dentin bağlanma dayanımlarını artırmaz.

\section{GEREÇ VE YÖNTEM}

\section{Test materyalleri}

Bu çalışmada, piyasada mevcut olan üç adet kendinden bağlanabilen akışkan kompozit [Vertise Flow, Kerr, Orange, CA, ABD; Fusio Liquid Dentin, Pentron Clinical, Orange, CA, ABD; Nova Compo SF, Imicryl AS, Konya, Türkiye] kullanıldı (Tablo 1). Kollajen çapraz bağ ajanı olarak kullanılan solüsyon için proantosiyanidin içeren toz haldeki üzüm çekirdeği özütü (HerbStore, ABD) ve çözücü olarak \%100 aseton (BDH Prolabo, Fransa) kullanıldı. Proantosiyanidinden zengin 20 gram üzüm çekirdeği özütü $100 \mathrm{ml}$ aseton ile karıştırıldı. Karışım, asetonun buharlaşmaması için kapağı sızdırmaz bir cam kap içinde yapıldı. Çözünmeyen üzüm çekirdeği özütü; homojen, partikülsüz bir solüsyon oluşturmak amacıyla filtre kağıdıyla filtrelenerek uzaklaştııı ve sonuçta \%20'lik proantosiyanidin solüsyonu elde edildi.

Tablo 1.

\section{Çalışmada kullanılan kendinden bağlanabilen akışkan kompozitler}

\begin{tabular}{|c|c|c|c|c|}
\hline Materyal & $\begin{array}{l}\text { Ürün kodu / } \\
\text { renk tonu }\end{array}$ & $\begin{array}{l}\text { Üretici } \\
\text { firma }\end{array}$ & $\begin{array}{l}\text { Organik } \\
\text { matriks }\end{array}$ & Doldurucular \\
\hline $\begin{array}{l}\text { Vertise } \\
\text { Flow }\end{array}$ & 4732415/A2 & $\begin{array}{c}\text { Kerr, } \\
\text { Orange, } \\
\text { CA, ABD }\end{array}$ & $\begin{array}{l}\text { GPDM, Bis- } \\
\text { GMA, } \\
\text { HEMA, } \\
\text { metakrilat } \\
\text { ko- } \\
\text { monomerleri }\end{array}$ & $\begin{array}{c}\text { Prepolimerize } \\
\text { doldurucular, } 1 \mu \mathrm{m} \\
\text { baryum cam, } \\
\text { nanoboyutlu } \\
\text { koloidal silika, } \\
\text { nanoboyutlu } \\
\text { ytterbium florid }\end{array}$ \\
\hline $\begin{array}{l}\text { Fusio } \\
\text { Liquid } \\
\text { Dentin }\end{array}$ & $4447169 / \mathrm{A} 2$ & $\begin{array}{l}\text { Pentron } \\
\text { Clinical, } \\
\text { Orange, } \\
\text { CA, ABD }\end{array}$ & $\begin{array}{l}\text { UDMA, } \\
\text { TEGDMA, } \\
\text { HEMA, 4- } \\
\text { MET }\end{array}$ & $\begin{array}{l}\text { Nanoboyutlu } \\
\text { amorfoz } \\
\text { silika,silan kaplı } \\
\text { baryum cam }\end{array}$ \\
\hline $\begin{array}{l}\text { Nova } \\
\text { Compo } \\
\text { SF }\end{array}$ & $16008 / \mathrm{A} 2$ & $\begin{array}{l}\text { Imicryl, } \\
\text { Konya, } \\
\text { Türkiye }\end{array}$ & $\begin{array}{l}\text { 10-MDP, 4- } \\
\text { META }\end{array}$ & $\begin{array}{c}\text { Hidrofilik alifatik } \\
\text { dimetakrilat, } \\
\text { hidrofobik alifatik } \\
\text { dimetakrilat, } \\
\text { dimetakrilat,ba- } \\
\text { cam, } \\
\text { floroaluminasilikat }\end{array}$ \\
\hline
\end{tabular}

\section{Örnek hazırlma}

Deney için 90 adet çürüksüz insan daimi molar dişi kullanıldı. Su soğutması altında düşük hızda dönen elmas separe (Isomet; Buehler, Lake Bluff, IL, ABD) ile okluzal mine yüzeyi kaldırılarak dişlerin orta koronal dentin yüzeyleri açığa çıkarıldı. Hazırlanan dentin yüzeyleri açıkta kalacak şekilde dişler silindirik akrilik bloklara gömüldü. Örneklerin düz dentin yüzeyleri \#600 grenli zımpara kâğıdı ile zımparalanarak standart smear tabakası oluşturuldu ve daha sonra rastgele 6 gruba ayrildı $(n=15)$. Deney gruplarına ait dentin yüzeylerine kendinden bağlanabilen akışkan kompozitleri bağlamadan önce bu yüzeyler \%20'lik 
proantosiyanidin solüsyonu ile 1 dakika muamele edildi. Kontrol gruplarına ait dentin yüzeylerine herhangi bir işlem uygulanmadı. Daha sonra kendinden bağlanabilen akışkan kompozitler $2.34 \mathrm{~mm}$ çapında, $3 \mathrm{~mm}$ yüksekliğinde standart silindir şekilli plastik matris (Ultradent, South Jordan, ABD) içerisine yerleştirildi. Akışkan kompozitler plastik matris içerisine yaklaşık 1,5 mm'lik iki tabaka şeklinde yerleştirildi. İlk tabaka yerleştirildikten sonra fazla kompozit rezin bir sond yardımı ile matris etrafından dikkatlice temizlendi ve daha sonra okluzal yüzeyden 20 saniye süre ile Işıkla sertleştirildi (Valo, Ultradent, ABD). İkinci tabaka yerleştirildikten sonra yine okluzal yüzeyden 20 saniye süre ile ışıkla sertleştirildi. Işık cihazı, güç kaynağına bağlı olarak ve standart polimerizasyon modunda kullanıldı.

\section{Makaslama bağlanma dayanım testi}

Makaslama bağlanma dayanım testi öncesinde örnekler distile su içerisinde $37^{\circ} \mathrm{C}$ 'de 24 saat bekletildi. Makaslama bağlanma dayanım testi için örnekler üniversal test makinesine yerleştirildi. Her bir örneğin diş-kompozit ara yüzeyinde kırılma meydana gelene kadar $1 \mathrm{~mm} / \mathrm{dk}$ hızda kuvvet künt uçlu bir aparat (Ultradent, South Jordan, ABD) kullanılarak uygulandı. Gözlenen maksimum değer kompozit bloğun bağlanma yüzey alanına bölünerek MPa cinsinden makaslama bağlanma dayanım değeri elde edildi. Makaslama bağlanma dayanım verileri One-Way ANOVA ve Tukey's HSD Posthoc testleri ile analiz edildi.

\section{Kırılma Analizi}

Örneklerin kırılma tipleri bir stereomikroskop (Olympus SZ4045 TRPT, Osaka, Japonya; x20) altında belirlendi. Diş yüzeyinde kalan rezin miktarı \%80'den fazla ise koheziv kırılma, \%20'den az ise adeziv kırılma ve diğerleri de mix tipte kırılma olarak kaydedildi.

\section{BULGULAR}

Materyallerin makaslama bağlanma dayanım değerleri Tablo 2'de gösterildi. Dentinin üzüm çekirdeği özütü ile muamele edilmesi Nova Compo SF'nin ve Vertise Flow'un bağlanma dayanımını değiştirmedi $(p>0.05)$. Ancak, dentinin üzüm çekirdeği özütü ile muamele edilmesi Fusio Liquid Dentin'in dentine bağlanma dayanımını düşürdü $(p<0.05)$ (Tablo 2). Örneklerin kırılma tipleri Tablo 3'de gösterildi. Bütün örnekler adeziv tipte kırıldı, mix veya koheziv tipte kırılmaya rastlanmadı.
Tablo 2.

\section{MPa olarak ortalama ( \pm standart sapma) makaslama bağlanma dayanım değerleri}

\begin{tabular}{|c|c|c|c|}
\hline Materyal & $\mathbf{N}$ & Kontrol & $\begin{array}{l}\text { Üzüm } \\
\text { çekirdeği } \\
\text { özütü }\end{array}$ \\
\hline $\begin{array}{l}\text { Vertise } \\
\text { Flow }\end{array}$ & 15 & $3,29 \pm 1,64$ & $2,67 \pm 2,88$ \\
\hline $\begin{array}{l}\text { Fusio } \\
\text { Liquid } \\
\text { Dentin }\end{array}$ & 15 & $7,84 \pm 3,93$ & $3,27 \pm 1,78^{\beta}$ \\
\hline $\begin{array}{c}\text { Nova } \\
\text { Compo SF }\end{array}$ & 15 & $8,23 \pm 4$ & $9,70 \pm 4,50$ \\
\hline
\end{tabular}

${ }^{\beta}$ Kontrol ile karşıllaştıııldığında $p<0.05$.

Tablo 3.

Makaslama bağlanma dayanım testi sonrası test örneklerinin kırılma tipleri

\begin{tabular}{|c|c|c|c|c|c|c|}
\hline \multirow{2}{*}{ Gruplar } & \multicolumn{3}{|c|}{ Kontrol } & \multicolumn{3}{|c|}{ Üzüm çekirdeği özütü } \\
\hline & Adeziv & Koheziv & Mix & Adeziv & Koheziv & Mix \\
\hline $\begin{array}{c}\text { Vertise } \\
\text { Flow }\end{array}$ & $15(\% 100)$ & $0(\% 0)$ & $0(\% 0)$ & $15(\% 100)$ & $0(\% 0)$ & $0(\% 0)$ \\
\hline $\begin{array}{l}\text { Fusio } \\
\text { Liquid } \\
\text { Dentin }\end{array}$ & $15(\% 100)$ & $0(\% 0)$ & $0(\% 0)$ & $15(\% 100)$ & $0(\% 0)$ & $0(\% 0)$ \\
\hline $\begin{array}{c}\text { Nova } \\
\text { Compo } \\
\text { SF }\end{array}$ & $15(\% 100)$ & $0(\% 0)$ & $0(\% 0)$ & $15(\% 100)$ & $0(\% 0)$ & $0(\% 0)$ \\
\hline
\end{tabular}

\section{TARTIŞMA}

Kendinden bağlanabilen akışkan kompozitler piyasaya yeni sunulmuş ve halen geliştirilmekte olan materyallerdir. Literatürdeki az sayıda çalışma incelendiğinde bu akışkan kompozitlerin bağlanma dayanımları ile ilgili tatmin edici sonuçlar alınamadığı sonucuna varılabilir. Bu durumda, ya materyallerin daha da geliştirilmesi, ya ayrı bir adeziv sistem ile birlikte uygulanması ya da kompozitlerin uygulandığı yüzeylerin çeşitli işlemlere tabi tutulması gerekliliği ortaya çıkmıştır denilebilir (Poitevin ve ark. 2013, Simsek Derelıoglu ve ark 2014). Son yıllarda rezin ile dentin arasındaki bağlantı kuvvetinin arttırıması amacıyla kollajen çapraz bağ ajanı uygulaması gündeme gelmiştir (BedranRusso ve ark. 2011, Aguiar ve ark. 2014). Çalışmamızda kendinden bağlanabilen akışkan kompozitlerin dentine bağlanma dayanımlarına etkisini görmek için kollajen çapraz bağ ajanı olarak dentin yüzeylerine üzüm çekirdeği özütü (proantosiyanidin) uygulanmıştır.

Yeni geliştirilen restoratif materyallerin performanslarını in vitro çalışmalarla kısa sürede test etmek, klinik kullanımlarını desteklemek açısından yol gösterici olabilmektedir (Van Meerbeek ve ark. 1998, Van Meerbeek ve ark. 2003). In vitro makaslama bağlanma dayanım testi, 
rezin esaslı restoratif materyallerinin diş sert dokularına bağlanma performanslarını karşılaştırmada ve değerlendirmede yeterli ve etkin yöntemdir (DeHoff ve ark. 1995, Mason ve ark. 1996, Lopes ve ark. 2002). Bu in vitro çalışmada da çalışmaya dâhil edilen kendinden bağlanabilen akışkan kompozitlerin dentin bağlanma dayanımları, makaslama bağlanma testi ile değerlendirilmiştir.

Bu çalışmada kompozit rezinler dentin yüzeylerine standart silindirik şekilli plastik matrisler içerisinden uygulandı. Böylece bağlanma yüzey alanı, kompozit rezinin kalınlığı ve ışık kaynağının polimerize edilen kompozite olan uzaklığı oldukça iyi bir şekilde standardize edilebildi. Sonrasında makaslama bağlanma dayanım testleri klasik bıçak gibi keskin uçlu aygıt yerine, ucu künt ve yarım ay şeklinde çentikli bir aygıt (Ultradent makaslama bağlanma dayanım test aygıtı) ile gerçekleştirildi. Bu test aygıtı dentine bağlanmış ve polimerize edilmiş kompozit test bloğunun etrafını $180^{\circ}$ sarmakta ve böylece daha geniş bir alanda temas sağlayarak uygulanan makaslama kuvvetini kompozit bloğun etrafında daha geniş bir sahaya yayabilmektedir (DeHoff ve ark. 1995).

Pek çok meyve, sebze, yemiş, çekirdek ve tohum proantosiyanidin kaynağı olarak gösterilse de en çok kakao bitkisi tohumunda, çam ağacı kabuğunda ve üzüm çekirdeğinde bulunduğu bildirilmiştir (Rapport ve Lockwood 2001). Üzüm çekirdeği özütünün \%95 ile \%99 oranında proantosiyanidin bulundurabileceğini, bu oranın diğer bitki özütlerine göre en yüksek değer olduğu rapor edilmiştir (Fine 2000). Bu sebeple bu çalışmada \%95 oranında proantosiyanidin içeren üzüm çekirdeği özütü kullanılmıştır.

Proantosiyanidinin bitkisel ürünlerden en yüksek oranda elde edilmesi için uygun bir çözücünün kullanılması gerektiği savunulmuştur. Metanol, etanol, aseton ve bunların su ile değişik oranlarda karışımlarından oluşan çözücülerin kullanılabileceği bildirilmiştir (Pekic ve ark. 1998). Aseton içerikli çözücülerin proantosiyanidin içerikli özütler için diğer çözücülerden daha başarılı sonuç verdiğini gösterilmiştir (Liu ve ark. 2011). Bizim çalışmamız da Fang ve ark. (2012)'nın çalışmasına benzer şekilde proantosiyanidin solüsyonu elde edebilmek için proantosiyanidinden zengin üzüm çekirdeği özütü \%100 aseton içinde bekletildi ve çözünmeyen üzüm çekirdeği özütü homojen bir solüsyon elde edebilmek amacıyla filtre kağıdı kullanılarak filtrelendi ve solüsyondan uzaklaştıııldı.

Çalışmamızda kendinden bağlanabilen akışkan kompozit olarak Vertise Flow, Fusio Liquid Dentin ve Nova Compo SF kullanıımışıtı. Bu çalışmanın laboratuvar çalışmaları yürütüldüğü sırada Nova Compo SF materyali üretici firma Imicryl tarafından geliştirilmiş fakat henüz piyasaya sürülmemişti. Bu yüzden bu çalışmada Nova Compo SF örnekleri deneysel Nova Compo SF materyalinden elde edilmiştir.

Ayrı bir adeziv sistem ile dentine bağlanan materyaller ile yapılan çalışmalarda proantosiyanidinin dentine bağlanmayı artırdığı yada uzun dönemde bağlantının stabil kalmasını sağladığı görülmektir. Örneğin, kök kanal dentini ile adezivden oluşan arayüzün bağlanma dayanımının stabilize edilmesinde, adeziv uygulamadan önce proantosiyanidin ile muamele edilmesinin etkili olduğu bildirilmiştir (Cecchin ve ark. 2015). Asitle ve yıka adeziv uygulamasından önce proantosiyanidin ile muamelenin koronal dentinde uzun dönem bağlantının stabil kalmasını sağladığı bildirilmiştir (Verma ve ark. 2013). Diğer taraftan, kendinden asitli (self-etch) adezivlerinderin koronal dentine bağlanma dayanımı artırmada proantosiyanidinin etkili olduğu bildirilmiştir (Srinivasulu ve ark. 2013).

Bizim bulgularımızla benzer şekilde, ayrı bir adeziv sistem kullanımı gerektirmeyen kendi bağlanabilen rezin simanların dentin bağlanma dayanımına proantosiyanidin ile dentin ön muamelenin herhangi bir katkı sağlamadığı bildirilmiştir (Broyles ve ark. 2013). Farklı tip çapraz bağlayıcılar ve bunların farklı konsantrasyonlarının dentin bağlanma dayanımına etkisi değerlendirilebilir.

Dentin makaslama bağlanma dayanımının performansında bir artış elde edemeyişimizin bir diğer nedeni de, dentin yüzeyinin sadece $1 \mathrm{dk}$ gibi kısa süre ile proantosiyanidine maruz bırakılmış olması olabilir. Hâlbuki, literatürdeki diğer çalışmalarda $2 \mathrm{dk}, 5 \mathrm{dk}, 10$ dk ve $30 \mathrm{dk}$ gibi uzun süreler test edildiğinde başarıı sonuçlar alınmıştır (Bedran-Russo ve ark. 2008, Srinivasulu ve ark. 2013).

\section{SONUÇ}

Kollajen çapraz bağ ajanı olarak kullanılan \%20'lik üzüm çekirdeği özütü, kendinden bağlanabilen akışkan kompozitlerin dentine bağlanma dayanımlarını arttırmadı. Dahası, Fusio Liquid Dentin'in dentine bağlanma dayanımını olumsuz etkiledi. Kendinden bağlanabilen akışkan kompozitlerin bağlanma dayanımlarını artırmak amacıyla; bu çalışmada kullanılan doğal kollajen çapraz bağlayıcı ajanla oluşturulan solüsyonların farklı süre ve konsantrasyonlarıly ya da başka kollajen çapraz bağlayıcı ajanlarla yeni çalışmalar yapılması düşünülebilir. 


\section{KAYNAKLAR}

Aguiar TR, Vidal CM, Phansalkar RS, Todorova I, Napolitano JG, McAlpine JB, Chen SN, Pauli GF, Bedran-Russo AK, 2014. Dentin biomodification potential depends on polyphenol source. J DentRes, 93(4), 417-422.

Bedran-Russo AK1, Pashley DH, Agee K, Drummond $\mathrm{JL}$, Miescke KJ, 2008. Changes in stiffness of demineralized dentin following application of collagen crosslinkers. J Biomed Mater Res B ApplBiomater, Aug, 86(2), 330-334.

Bedran-Russo AK, Castellan CS, Shinohara MS, Hassan L, Antunes A, 2011. Characterization of biomodified dentin matrices for potential preventive and reparative therapies. ActaBiomaterialia, 7(4), 1735-1741.

Bedran-Russo AK, Pauli GF, Chen SN, McAlpine J, Castellan CS, Phansalkar RS, Aguiar TR, Vidal CM, Napotilano JG, Nam JW, Leme AA, 2013. Dentin biomodification: strategies, renewable resources and clinical applications. Dent Mat, 30(1), 62-76.

Belli S, ÜlkerM, 2015. Adeziv bağlayıcı sistemler üzerine bir güncelleme. G MAG Dişhekimliği Dergisi, $1,38-45$.

Broyles AC, Pavan S, Bedran-Russo AK, 2013. Effect of dentin surface modification on the microtensile bond strength of self-adhesive resin cements. Journal of Prosthodontics, 22(1), 59-62.

Cardoso MV, de AlmeidaNeves A, Mine A, Coutinho E, Van Landuyt K, De Munck J, Van Meerbeek B, 2011. Current aspects on bonding effectiveness and stability in adhesive dentistry. AustralianDentalJournal, 56, (1 Suppl), 31-44.

Cecchin D, Pin LC, Farina AP, Souza M, VidalCde M, Bello YD, Ferraz CC, Bedran-Russo A, 2015. Bond strength between fiber posts and root dentin treated with natural cross-linkers. J Endod, Oct, 41(10), 16671671.

DeHoff PH, Anusavice KJ, Wang Z, 1995. Threedimensional finite element analysis of the shear bond test. Dent Mater, 11, 126-131.

Fang M, Liu R, Xiao Y, Li F, Wang D, Hou R, Chen J, 2012. Biomodification to dentin by a natural crosslinker improved the resin-dentin bonds. J Dent, 40(6), 458-466.

Fine AM, 2000. Oligomeric proanthocyanidin complexes: history, structure, and phytopharmaceutical applications. AlternMedRev, 5(2), 144-151.
Goracci C, Margvelashvili M, Giovannetti A, Vichi A, Ferrari M, 2013. Shear bond strength of orthodontic brackets bonded with a new self-adhering flowable resin composite. Clin Oral Invest, 17(2), 609-617.

Liu Y, Tjäderhane L, Breschi L, Mazzoni A, Li N, Mao J, Pashley DH, Tay FR, 2011. Limitations in bonding to dentin and experimental strategies to prevent bond degradation. J DentRes, 90(8), 953-968.

Lopes GC, Baratieri LN, de Andrada MA, Vieira LC, 2002. Dental adhesion: present state of the art and future perspectives. Quintessencelnt, 33(3), 213224.

Mason PN, Ferrari M, Cagidiaco MC, Davidson CL, 1996. Shear bond strength of four dentinal adhesives applied in vivo and in vitro. J Dent, 24(3), 217-222.

Pekic B, Kovac V, Alonso E, Revilla E, 1998. Study of thee xtraction of proanthocyanidins from grape seeds. FoodChemistry, 61, 201-206.

Poitevin A, De Munck J, Van Ende A, Suyama $Y$, Mine A, Peumans M, Van Meerbeek B, 2013. Bonding effectiveness of self-adhesive composites to dentin and enamel. DentalMaterials, 29(2), 221230

Poss SD, 2010. Utilization of a new self-adhering flowable composite resin. DentToday, 29,104-105.

Rapport L, Lockwood B, 2001. Proanthocyanidins and grape seed extract. Pharm J, 266, 581-584.

Simsek Derelioglu S, Yilmaz Y, Celik P, Carikcioglu $B$, Keles S, 2014. Bond strength and microleakage of self-adhesive and conventional fissure sealants. DentalMaterialsJournal, 33(4), 530-538.

Srinivasulu S, Vidhya S, Sujatha M, Mahalaxmi S, 2013. Effectof collagen cross-linkers on the shear bond strength of a self-etch adhesive system to deep dentin. J ConservDent., Mar, 16(2), 135-138.

Ulker M, Ozcan M, Sengün A, Ozer F, Belli S, 2010. Effect of artificial aging regimens on the performance of self-etching adhesives. J Biomed Mater Res B ApplBiomater, 93(1), 175-184.

Ülker M, Belli S, 2006. Self-etchadeziv sistemler: Diş sert dokularına bağlanma. SÜ Dişhek Fak Derg, 15, 116-122.

Van Landuyt KL, Snauwaert J, De Munck J, Peumans M, Yoshida Y, Poitevin A, Coutinho E, Suzuki K, Lambrechts P, Van Meerbeek B, 2007. Systematic review of the chemical composition of contemporary dental adhesives. Biomaterials, Sep, 28(26), 3757-3785. 
Van Meerbeek B, Perdigão J, Lambrechts $P$, Vanherle G, 1998. The clinical performance of adhesives. J Dent, 26(1), 1-20.

Van Meerbeek B, De Munck J, Yoshida Y, Inoue S, Vargas M, Vijay $P$, Van Landuyt $K$, Lambrechts $P$, Vanherle G, 2003. Buonocore memorial lecture. Adhesion to enamel and dentin: current status and future challenges. OperDent, 28(3), 215-35.

Van Meerbeek B, Van Landuyt K, De Munck J, Hashimoto M, Peumans M, Lambrechts P, Yoshida Y, Inoue S, Suzuki K, 2005. Technique-sensitivity of contemporary adhesives. Dent Mater J,24, 1-13.

Verma R, Singh UP, Tyagi SP, Nagpal R, Manuja N, 2013. Long-term bonding effectiveness of simplified etch-and-rinse adhesives to dentin after different surface pre-treatments. J ConservDent. Jul, 16(4), 367-370.

Vichi A, Margvelashvili M, Goracci C, Papacchini F, Ferrari $M, 2013$. Bonding and sealing ability of a new self-adhering flowable composite resin in class I restorations. Clin Oral Invest, 17(6), 1497-1506.

Yazışma Adresi:

Yrd.Doç.Dr. Firdevs KAHVECiOĞLU

Selçuk Üniversitesi

Diş Hekimliği Fakültesi Pedodonti AD

Selçuklu, Konya, Türkiye

Tel : + 903322231293

Faks : + 903322410062

E-mail: drfirdevskahveci@hotmail.com 